\title{
Leveraging Knowledge Transfer in Strategic Human Resource Management
}

\author{
Norfadzilah Abd Razak, Wan Edura Wan Rashid, Hairunnisa Ma'amor, Nini Hartini Asnawi, Nor Lela \\ Ahmad, and Nur'Ain Achim
}

\begin{abstract}
In this challenging business environment, development of human capital is crucial in order to sustain the highly skilled workforce to support the move towards greater productivity and higher value-added activities in Small Medium Enterprise (SMEs). Human capital development is a core element to sustain human capital inculcation of entrepreneurship culture as well as the development of strong entrepreneurial skills. The knowledge transfer model has been practised to ensure the objective of the human capital plan to be achieved through human resources process. Given the fact that knowledge transfer is the linkage of retaining and skills upgrading of human talent, this model is developed to fulfil the absence of producing knowledgeable human capital by concentrating on the knowledge infrastructure and knowledge process. In its essence, this framework shows how human resource processes apply the concepts of knowledge transfer model and address the consequences to SME sectors. Additionally, it can prove to be more innovative and may become a main contributor to economic development.
\end{abstract}

Index Terms-Knowledge transfer, human capital, strategic human resources.

\section{INTRODUCTION}

Small medium enterprises (SMEs) are usually defined as those that have sales of less than 2 million ringgit annually and have fewer than 100 employees [1]. The development of a feasible and active SME sector has been widely regarded as important to sustain economic change and organizational competitiveness in transformation economies [2]. In Malaysian economies, SMEs play an important role in terms of economic growth and providing human capital as they act as a pivotal role in the growth of domestic economy and to put Malaysia as more competitive other than developing into becoming a high income nation. They have become the prime mover and also the backbone of industrial development in Malaysia [3]. In the globalization of the world economy, a knowledge based economy urges the organization to enhance their employees' knowledge and skills through knowledge management, in order to survive, sustain and compete in the global environment [3]. The innovation and rapid development require accelerated use of knowledge that must be managed efficiently, effectively and securely. In this knowledge driven global economy, knowledge itself is a commodity that offers the only sustainable competitive edge. Simply, the employees of the organizations need to be more knowledgeable.

Knowledge workers are of critical importance to SMEs because of their knowledge and skills as a productive force

Manuscript received May 20, 2013; revised July 18, 2013.

Wan Edura Wan Rashid is with Business Management Universiti Teknologi Mara (e-mail: wanedura@yahoo.com). for the organizations. Furthermore, they are viewed as constituting an investment for an organization rather than just being a labour cost. Besides, their personal embodied knowledge is such that it represents a form of personal equity and as such means that many knowledge workers are potential entrepreneurs [4]. In today's economy, knowledge is one of the most important resources in creating a competitive advantage for the organization [5]. SMEs, therefore, must first know what their knowledge assets are. Subsequently, they must know how to manage and make use of these assets to get maximum returns [6]. Knowledge management (KM) has become an essential component of an organization which is beginning to change and strategize their planning as their focus [7].

The practice of $\mathrm{KM}$ in small and medium-sized enterprises (SMEs) differs from a large organization [8] (Wong and Aspinwall, 2004) because the size is different between SME and large organization. Furthermore, in certain behavioural advantages like rapid making decision, flexibility, less strict regulation, government support, fast communication, facilities and others [9], KM has been studied extensively. Nevertheless, most of the relevant research has concentrated on economic and political factors affecting SMEs [10] rather than human resource issues. Hence, the development of human capital in organizations has received less attention. Therefore, this study concentrates on the theory and concept in leveraging knowledge management through three main determinants of knowledge creation, dissemination, and absorptive ability in strategic human resource management. The importance of individual knowledge workers has been developed into the current theory of knowledge management and is therefore the main focus in the present study.

\section{Problem Statement}

SMEs have a problem of attracting high calibre, talented and experienced employees. These knowledge based people tend to go to larger organizations because of higher salaries and incentives, greater benefits as well as bonuses. Furthermore, it is also a problem for SMEs to retain specialized employees because of limited opportunities for career progression, and the constant appeal of organizations, that can provide better prospects. SMEs are mostly seen by some employees as a stepping-stone to move to the establish organization. The departure of highly knowledgeable employees is a major threat to SMEs, unless that knowledge is captured, codified, and transferred throughout the organization [11]. With a view to the above matters, SMEs has their constraint upon unique knowledge transfer challenges. Some of the inhibitors to transfer of knowledge within the organization are management's failure to signal 
the importance of the business. It means that there is vagueness of the objective, the mission or the goal to be achieved. A lack of ownership for a business problem or improvement opportunity to be addressed among the employees also contributes to the failure in knowledge transfer. Besides that, lack of contact and information exchange has been due to over-reliance on transmitting explicit information rather than tacit information. Most of the researchers also reported that time limitation disabled the employees and managers to being accustomed to seeking or sharing knowledge [12].

To sum up, the transfer of knowledge to SMEs can be problematic in terms of the lack of absorptive capacity [13] failures of the knowledge creator to disseminate knowledge to the employees [14]. The shortcomings include that of weakness in knowledge capabilities and process practices in the organization [15]. Most SMEs adopt short-term unstructured ways towards the transfer of knowledge [16]. Keeping this in mind, the aim of this paper is to conceptualize the knowledge transfer theory within SMEs to identify gaps in the field of strategic human resource as well as to clarify how knowledge transfer practices are effective in areas where no further research is needed for the time being.

\section{LITERATURE REVIEW}

\section{A. Theory of Knowledge Transfer}

In previous literature review of knowledge transfer theory, Nonaka Models of knowledge transfer are taken as a spiral process. It involves two types of knowledge known as tacit and explicit knowledge. In detail of this theory, there are four phases of categories which are socialization, externalization, internalization and combinations, all of which are involved actively in transfer the knowledge. Each phase of transfer operates differently. In Nonaka's Model, it defines socialization as a primary process of individual through direct interaction between external and internal to the organization. It explains that interaction is by sharing the experience and results in acquiring skills and common mental models. In the second mode of phases, externalization occurs when individuals within a group communicate and interact face-to-face to share beliefs and learn how to better communicate their thinking, through instant feedback and the simultaneous exchange of ideas.

Meanwhile, the combination is set aside by knowledge transfer among groups transversely in organizations through information technology. It is significant to transfer the explicit knowledge in documents, email, databases, as well as through meetings and briefings. Lastly, internalization involves the process of understanding and absorbing explicit knowledge into tacit knowledge to be practised in the actual situation, through the actual doing or through simulations. According to [17], the interactive is inclusive of transfer knowledge model which applies to the SME perspectives. For the study, the expert has developed and modified the theory from [18] and [19] who recently is actively conducting research in the theory of knowledge management. According to [18], the researcher develops three levels of involvement in the process of knowledge transfer which focus on the technology transfer that includes technology development, technology acceptance and technology application. In extension to [19], he had developed a model named as Contingent Effectiveness Model of Technology Transfer which basically depends on the (1) actors as the transfer agent, who generates and disseminates the knowledge, (2) transfer recipient, the individual or organization that tries to incorporate the knowledge into their own products and production processes and finally (3) transfer channel through which the results are disseminated and that includes that of economic environment in which the transfer takes place are important features of technology transfer model.

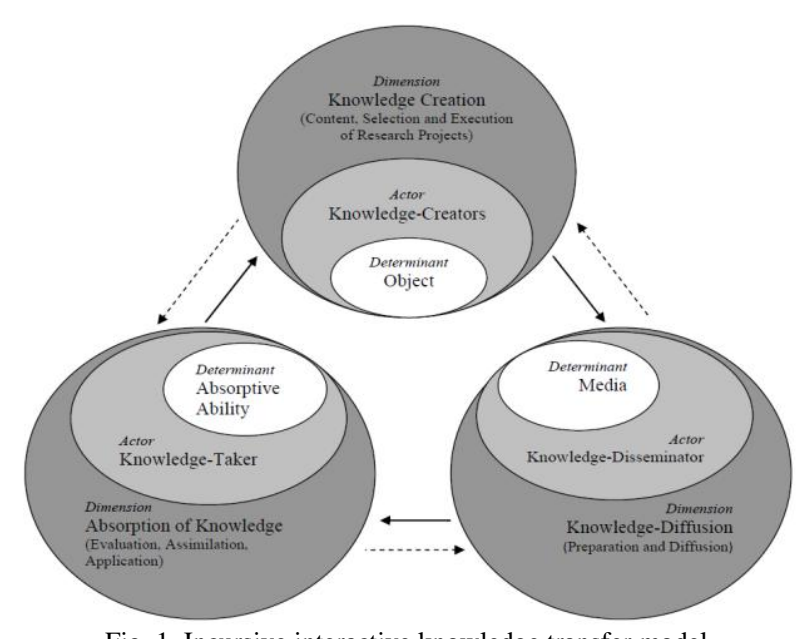

Fig. 1. Incursive interactive knowledge transfer model.

According to the finding by [17], the expert adopted the two theories and developed inclusive interactive knowledge transfer model as presented in Fig. 1 below. This model identifies three domains of knowledge transfer which consists of knowledge creation, knowledge taker and knowledge diffusion. In his literature review, [17] defines knowledge-creators as a person who is actively involved in the creation of knowledge. Meanwhile, knowledge disseminates to those who are actively involved in the dissemination process of knowledge and finally knowledge takers are those who accept and absorb the generated and disseminated knowledge. The relationship between knowledge creators, knowledge disseminators and knowledge takers are reflected in the procedural character of the three dimensions. The transfer model developed by [17] is significantly and widely being practised by most of the organizations and applicable to various industries that include small media entrepreneur through human resource management. The human resource management plays a vital role to ensure the effectiveness and the successful implementation of knowledge transfer towards their human capital in achieving the organizational goals.

\section{B. Strategic Human Resource Management and Knowledge Transfer}

In the fundamental nature of Human Resource Management (HRM), it is a systematic process of preparing competencies and knowledge human capital through selection and recruitment, human development, performance appraisal and other related processes. Furthermore, HRM is also defined as a particular set of practices potentially to improve the organizational performance [20]. According to 
previous literature review, many researchers define the set of practices typically that includes teamwork, performancerelated pay; ability to making decisions comprehensive employee recruitment and selection procedures; limited status differences; extensive training; employee involvement and internal communication arrangements; internal career opportunities; and broadly defined job descriptions [21][23].

Therefore, strategies of human resources are vital in planning and organizing human capital to sustain their human capital for the future and achieve the organization goal. To sum up the discussion, there are three conclusions made. Firstly, HRM usually puts emphasis on enhancing employee abilities or knowledge and skills through effective recruitment and strong training. Secondly, the HRM emphasises on motivating desired behaviour through strong incentives. Finally, best practice models promote opportunities for better trained and motivated workers to contribute to their knowledge and skills through work redesign and involvement of employee in the organization [24].

Based on the concept of human resource management, this study extends the practices of human resources in leveraging the knowledge transfer to produce the knowledge skill and human capital. In the literature review related to this study, many researchers claimed that human resources practices play an important role in facilitating employees' absorption, transfer, sharing and creation of knowledge [25]. Previously, many researchers neglect to conduct research on the human capital issue [26]. The literature of knowledge transfer has made only partial and limited use of HRM concepts and frameworks [27]. However, there have been researchers who have started to explore the correlation of the knowledge transfer and human resource process critically, dependent on having suitably motivated people taking an active role in the process [28].

Due to the significance of this wide study, most of the human resources manager's believe that the knowledge transfer study will contribute to retain and sustain the knowledge and skill of the human capital in the organization. Alternatively, knowledge transfer involves the personal nature of the tacit knowledge which requires willingness on the part of those workers who possess it to share and communicate it [29]-[31]. According to [32] it is also highlighted that the contribution of human resource practices to manage knowledge is determined by the employees' unwillingness to share knowledge with others.

To sum up this discussion [33] it has been supported that a HRM practice plays an important role in facilitating employees' absorption, transfer, sharing and creation of knowledge. The researcher pinpoints the importance that HRM plays in identifying the practices of the tacit knowledge, the best practices of utilization involving negotiating with employees on selecting an appropriate knowledge transfer program, harnessing a know-how strategy, creating a supportive environment for knowledge transfer programs, enabling technologies for a knowledge transfer program and creating a team. According to [34], it has also been agreed that strategic human resource in compensation, training and performance management programs significantly affect employee motivational behaviours to participate in knowledge transfer activities.

Similarly, [35] belief and support that HRM practices such as selection methods, compensation strategies and career systems seem to have an influence on maximizing the knowledge transfer towards human capital. According to [36], it adds to this discussion by finalizing that human beings are the critical knowledge creators and bearers. Great care has to be taken to increase human capability and organizational performance. This requires creating knowledge enhancers and significant result through the rigorous and strategic management of people toward effective leveraging knowledge transfer process.

\section{CONCEPTUAL FRAMEWORK}

Consequently, in this study the determinants of knowledge transfer influence the practices of human resources management to understand how the knowledge transfer role are being practised in the human resources management in SMEs.

Fig. 2 illustrates the conceptual framework which has been adapted from the study of a future for human resources a specialized Role in Knowledge Management [37]. The proposed concepts involved the human resources process and knowledge transfer model for best practices in the organization. The human resources practice involves can be summed up to the recruitment and selection (R\&S), human resources development (HRD), succession planning (SP) and performance appraisal (PA). In other perspectives the determinants of the knowledge transfer model consist of knowledge taker, knowledge creation and knowledge dissemination which actively include knowledge capabilities, infrastructures and knowledge capabilities process. This knowledge transfer model has been explained by which five dimensions were selected to measure knowledge transfer process capabilities namely acquisition, conversion, application, protections and storing. Meanwhile, there are four dimensions selected to measure infrastructure which is a capability. These dimensions comprise technology, structure, culture and human resources [38].

Proposed Conceptual Framework:

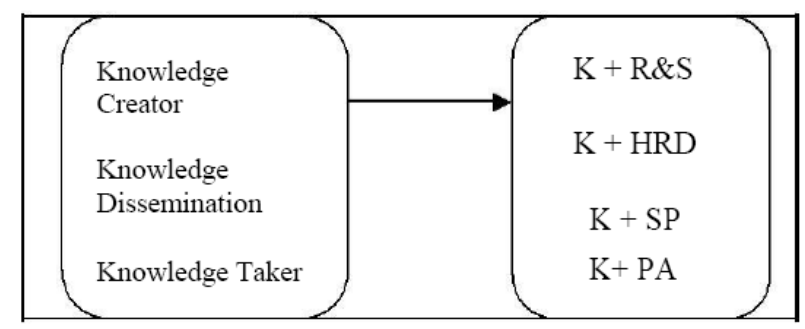

Fig. 2. The process involved between knowledge transfer and human resources process at small medium enterprises (SMEs).

Based on the framework above, several hypotheses will be tested, as listed below:

- H1: There is a significant relationship that exists between the human resources process and the degree of implementation of knowledge transfer taking place towards employees.

- H2: Knowledge transfer is significantly being practised in the human resources process. 


\section{DISCUSSION AND RECOMMENDATION}

In the context of recruitment and selection, there is the process of finding, as well as selection of the right people with the right qualifications, skills, attitudes and traits to do a particular job [39]. Basically recruitment process would look for individual who are willing and able to help convert tacit into explicit knowledge. Implication to the process of knowledge transfer, competencies of employees to share knowledge, disseminate and usage of the knowledge is an important and integral principle to the recruitment process. In turn, with knowledge-committed employee, the recruitment functions actively recruit people who are committed to the principle of sharing what they know, for the benefit of other individuals in the organization, and the organization itself. Different practices of performance appraisals indicate that it is purposely to determine on how well employees are doing their job, as well as establishing a plan for future performance improvement [39]. This involves the significance towards the knowledge transfer practices. A person's contribution to the creation of a knowledge culture could also be appraised and rewards to be awarded to the employees for better incentives. To create an environment that encourages the generation of new ideas, sharing the idea, evaluate and disseminate the idea, managers should consider incentive pay for ideas generated, no layoffs for productivity improvements that follow from these new ideas and others related [40].

Besides that, training and development is a process to generate new ideas whereas employees need to be trained in problem solving, including an ability in critical thinking and to share knowledge in expressing idea through proper medium. In addition, the employees also need to be trained to evaluate the idea in prodding the decision-making skill and problem solving. It is also helpful that the employee disseminates and adopts new idea through active learning in organization to implement and practise the gained knowledge [40] Theoretically, it converts tacit into explicit knowledge; retain the tacit knowledge of those people about to leave the organization; use the available explicit knowledge in day-to-day processes and decision-making; and measure the achievement of the organization in converting, retaining and using existing as well as new knowledge [41]. Succession planning is the strategy to prepare the next employees to manage the organization. HR manager's roles are to ensure that the organization's future managers receive the necessary preparation to successfully fill potential vacancies [42]. In the knowledge organization, it is part of preparation in which the management is potential to develop positive attitudes that contribute their own knowledge and experiences with the organization as well as encouraging these attitudes and behaviours in others. Significant to the succession planning practices, the organization focuses on the continuous learning organization as the channel to implement the knowledge transfer.

\section{CONCLUSION}

In conclusion, as much importance is on the theory, the knowledge transfer model comprises knowledge creator, knowledge dissemination and knowledge taker, are as important to practices in the human resources process. There are many issues and problems arising in retaining the knowledge based worker to sustain for the next development particularly in context of SMEs. There are many barriers and weaknesses in which the organization neglects to implement knowledge transfer. However, many researchers agree that implementation of knowledge transfer in the organization will improve the organizational and individual performance and will directly encourage the innovative and creativity among the employees in the organization. Many of them believe that the contents of knowledge to be created, shared and used among the employees are to sustain human capital development.

In order to strategise best practices and effective human resource management, knowledge transfer is the key element to be considered by concentrating to analyse the infrastructures and processes involved in transfer of knowledge. The knowledge infrastructures include the organization structure, technology use and culture play vital roles to ensure the process of knowledge transfer towards the employees are well effective. Nevertheless, knowledge process such as acquisitions, conversions, application and protection perceived as the systematic process guide the organization to implement the transfer of knowledge through human resources process. The theory of knowledge transfer cannot afford to ignore the value that can be gained from the context of human resources practitioners.

Given the fact that knowledge transfer is the linkage of retaining and skills upgrading of human talent, it is vital to implement knowledge transfer for many reasons. It contributes towards the issues of employee recruitment, training and development, succession planning, and performance appraisal. This is turn influences how the organizations develop and practise knowledge transfer basis. This indirectly influences strategies to retain human talent. Implementation of knowledge transfer might change the individual and organization capability with competitive advantages to compete with other businesses. It is also indicated in the small medium enterprises industry to be the main contributor to the business sector services and economic development.

\section{ACKNOWLEDGMENT}

This research was supported by the Research Management Institute (RMI) of Universiti Teknologi MARA, under the RAGS grant.

\section{REFERENCES}

[1] B. Delahaye, "Knowledge management in an SME," Drucker 1995, pp. 604-614.

[2] D. Pollard and I. Šimberová, "Researching the internationalization of SME's in the Czech Republic: some initial considerations," International Business in Transition Economies, vol. 1, no. 1, pp. 25 $35,2002$.

[3] T. T. Soon and F. A. Zainol, "Knowledge management enablers, process and organizational performance: evidence from Malaysian enterprises," Asian Social Science, vol. 7, no. 8, pp. 186-202, 2011.

[4] C. Carter and H. Scarbrough, "Towards a second generation of KM? The people management challenge," Education \& Training, vol. 43, no. 4-5, pp. 215-224, 2001

[5] M. A. Hitt, R. D. Ireland, and R. E. Hoskisson, Strategic Management: Competitiveness and Globalization, 3rd ed., SouthWestern College Publishing, Cincinnati, OH, 1999. 
[6] K. Rajender and B. Management, "Knowledge management practices in SME sector an empirical study," Rajender, K., \& Management, B. (n.d.), Knowledge Management Practices in SME Sector An Empirical Study, vol. 2, no. 4, pp. 1-9, 2012.

[7] V. Supyuenyong, N. Islam, and U. Kulkarni, "Influence of SME characteristics on knowledge management processes: The case study of enterprise resource planning service providers," Journal of Enterprise Information Management, vol. 22, no. 1-2, pp. 63-80, 2009.

[8] K. Y. Wong and E. Aspinwall, "Characterizing knowledge management in the small business environment," Journal of Knowledge Management, vol. 8, no. 3, 2004.

[9] K. Choochote and R. Nurse, Model for SMEs in Developing Countries, pp. 189-192, 2012.

[10] L. T. Szamosi, L. Duxbury, and C. Higgins, "Toward an understanding of people management issues in SMEs: A southeastern European perspective," Education \& Training, vol. 46, no. 8-9, pp. $444-453,2004$.

[11] S. Durst and I. R. Edvardsson, "A literature review knowledge management in SMEs: A literature review," Journal of Knowledge Management Emerald Article: Knowledge Management in SMEs, 2012.

[12] C. Ashton and L. Morton, "Managing talent for competitive advantage," Strategic HR Review, vol. 4, no. 5, pp. 28-31, 2005.

[13] S. A. Zahra and G. George, "Absorptive capacity: A review, reconceptualization, and extension," Academy of Management Review, vol. 27, no. 2, pp. 185-230, 2002.

[14] R. Woodward, "SME support institutions in post-communist countries: Moving beyond individual approaches to development cooperation: Reflections based on the case of Poland," presented at the Third Enterprise in Transition Conference, Hvar, Croatia, May 2001.

[15] M. Osterloh and B. S. Frey, "Motivation and knowledge transfer," Organization Science, vol. 11, no. 5, pp. 537-550, 2000.

[16] V. Hutchinson and P. Quintas, "Do SMEs do Knowledge Management? Or simply manage what they know?" International Small Business Journal, vol. 26, no. 2, pp. 131-154, 2008.

[17] V. C. Eckl, Creating an Interactive-Recursive Model of Knowledge Transfer, 2012.

[18] D. V. Gibson and E. M. Rogers, "R\&D collaborations on trial. The microelectronics and computer technology corporation," Boston MA, Harvard Business School Press, 1994.

[19] B. Bozeman, "Technological transfer and public policy: a review of research and theory," Research Policy, vol. 29, no. 4-5, pp. 627-655, 2000.

[20] M. Marchinton and A. Wilkinson, "People management and development: human resource management at work," 2nd ed., CIPD, London, 2003.

[21] D. E. Guest, J. Michie, N. Conway, and M. Sheeman, "Human resource management and corporate performance in UK," British Journal of Industrial Relations, vol. 41, no. 2, pp. 291-314, 2003.

[22] J. Michie and M. Sheehan, "Business strategy, human resources, labour market flexibility, and competitive advantage," International Journal of HRM, vol. 16, no. 3, pp. 445-64, 2005.

[23] J. M. P. de Kok, L. M. Uhlaner, and R. A. Thurik, "Professional HRM practices in family owned-managed enterprises," Journal of Small Business Management, vol. 44, no. 3, pp. 441-60, 2006.

[24] P. Boxal and J. Purcel, Strategy and Human Resource Management, Palgrave Macmillan, New York, NY, 2003.

[25] F. Soliman and K. Spooner, "Strategies for implementing knowledge management: role of human resources management," Journal of Knowledge Management, vol. 4, no. 4, pp. 337-45, 2000.

[26] V. Oltra, "Knowledge management effectiveness factors: the role of HRM," Journal of Knowledge Management, vol. 9, no. 4, pp. 70-86, 2005 .
[27] D. Hislop, "Linking human resource management and knowledge management via commitment: a review and research agenda," Employee Relations, vol. 25, no. 2, pp. 182-202, 2003.

[28] R. Reynolds and A. Ablett, "Transforming the rhetoric of organizational learning to the reality of the learning organization," The Learning Organization, vol. 5, no. 1, pp. 24-35, 1998

[29] P. Flood, T. Turner, N. Ramammorthy, and J. Pearson, "Causes and consequences of psychological contracts among knowledge workers in the high technology and financial services industry," International Journal of Human Resource Management, vol. 12, no. 7, pp. 1152 1161, 2001.

[30] L. Empson, "Fear of exploitation and fear of contamination: impediments to knowledge transfer in mergers between professional service firms," Human Relations, vol. 54, no. 7, pp. 839-862, 2001.

[31] P. Willman, F. M. O'Greevy, N. Nicholson, and E. Soane, "Knowing the risks: theory and practice in financial market trading," Human Relations, vol. 54, no. 7, pp. 887-910, 2001.

[32] G. Currie and M. Kerrin, "Human resource management and knowledge management: enhancing knowledge sharing in a pharmaceutical company," International Journal of Human Resource Management, vol. 14, no. 6, pp. 1027-1045, 2003.

[33] F. Soliman and K. Spooner, "Strategies for implementing knowledge management: role of human resources management," Journal of Knowledge Management, vol. 4, no. 4, pp. 337-345, 2000.

[34] S. Greengard, "Storing shaping and sharing collective wisdom," Workforce, vol. 77, no. 10, pp. 82-88, 1998.

[35] H. Scarbrough, "Knowledge management, HRM and the innovation process," International Journal of Manpower, vol. 24, no. 5, pp. 501516, 2003.

[36] V. Oltra, "Knowledge management effectiveness factors: the role of HRM," Journal of Knowledge Management, vol. 9, no. 4, pp. 70-86, 2005.

[37] M. Tare, "A Future for human resources a specialised role in knowledge management," This thesis is submitted in fulfilment of the requirements for the Degree of Doctor of Philosophy in the School of Business, Swinburne University of Technology, vol. 13, 2003.

[38] A. N. H Zaied, An Integrated Knowledge Management Capabilities Framework for Assessing Organizational Performance, March 2013.

[39] R. J. Stone, Human Resource Management, 4th ed Milton Queensland John Wiley \& Sons, 2002.

[40] L. I. David and A. Gilbert, "Knowledge Transfer 2011," Center for Organization and Human Resource Effectiveness Briefing Paper Knowledge, 1998.

[41] T. T. Soon and F. A. Zainol, "Knowledge management enablers, process and organizational performance: evidence from Malaysian enterprises," Asian Social Science, vol. 7, no. 8, August 2011.

[42] W. M. Cohen and D. A. Levinthal, "Fortune favors the prepared firm," Management Science, vol. 40, no. 2, pp. 227-251, 1994.

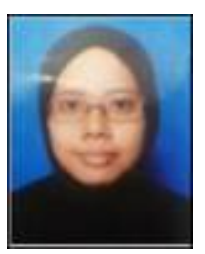

A. R. Norfadzilah was born at Kuantan, Pahang Malaysia at 24 November 1986, she hold master in Human Resources Management at Universiti Utara Malaysia, Sintok Kedah in year 2011. She is lecturer in Universiti Teknologi Mara at Campus Puncak Alam, Selangor Malaysia for 2 years. Previously she active conducted research on Emotional Intelligence. Recent to date, she concentrated to the research on Knowledge Transfer in Small Medium Enterprises. She had participated in International Invention, Innovation and Design 2013 at UiTM Perlis, Malaysia for An Innovation Knowledge Transfer Model and had been awarded for Bronze Medal. 